\title{
LXXIX. Notice on the chemical action of the magnetoelectric currents
}

\section{Professor Botto K.H. LL.D.}

To cite this article: Professor Botto K.H. LL.D. (1832) LXXIX. Notice on the chemical action of the magnetoelectric currents, Philosophical Magazine Series 3, 1:6, 441-442, DOI: $10.1080 / 14786443208647937$

To link to this article: http://dx.doi.org/10.1080/14786443208647937

册 Published online: 01 Jun 2009.

Submit your article to this journal

Џ Article views: 3

Q View related articles $₫$ 
if this space is left untouched, and the parts round it be covered by lines or etching, the figure will appear most luminous.

We would recommend this subject to the notice of the optician, as likely to furnish him with a lucrative article of trade.

Allerly, Nov. 8, 1832.

LXXIX. Notice on the Chemical Action of the Magnetoelectric Currents. By Professor Boтro, of Turin*.

A MONGST the characters which it is important to determine with reference to the knowledge of the nature of the magneto-electric currents discovered by Faraday, is that of their chemical action. As decisive of this point, I will state the results I have recently obtained, limiting myself for the present to a mere announcement; since they makepart of other results belonging to a series of careful experimental inquiries, intended to clear up certain points of the theory of electromagnetism, which will be published in due time.

The apparatus which I used to examine the chemical efficacy of the Faradian currents [Faradiane correnti] consisted principally of an artificial horse-shoe magnet, and a bar of soft iron surrounded in the middle by a magneto-electric spiral. The extremities of such a bar may, by help of a very simple arrangement, be separated at will from the poles of the magnet, and restored again to their first position with any required degree of rapidity.

The apparatus is inclosed within a wooden box, and is put into activity by an external handle. The box is surmounted by two rods, so connected (moveably) with the internal mechanism as by means of it to interrupt or re-establish the current, at pleasure, and at the moment most favourable to the production of a spark. When the spark is to be obtained, it is only necessary to connect these rods with the extremities of the magneto-electric spiral. When the apparatus is to be adjusted for chemical decomposition, the extremities are to be otherwise arranged, and so that the substance to be decomposed enters into the circuit.

Water, sulphate of copper, acetate of lead, and other salts in solution were thus submitted to trial. At first, minute quantities of the substances were acted upon, because of the feeble power of the apparatus (the magnet scarcely lifting six pounds, Piedmontese), and the presumed relative tenuity of the current: but I was not long in ascertaining that such was

* Communicated by the Author.

Third Series. Vol, 1. No. 6. Dec. 1832. 
the energy of the latter, that I could act with success on larger quantities.

Two platinum wires as conductors were fixed by cement in two holes made in the side of a small glass; the latter was then filled with water, made a better conductor by a few drops of solution of soda, and inverted in a vessel filled with the same fluid. The communication was then completed, between the platinum conductors, and the extremities of the rods connected with the magneto-electric spiral, and the apparatus was worked. So soon as the successive detaching and attaching action began, the divellent forces of the platinum poles became evident, and an infinity of gaseous bubbles rose from them in the form and appearance of two columns of vapour: in a short time these being collected in the top of the glass, produced a portion of oxygen and hydrogen capable of causing a sensible detonation.

The phænomena became even more interesting, when the evolution of the two gases was observed through a powerful lens; the bubbles succeeding each other the more vigorously as the alternate action of the magneto-electrometer is more rapid. My colleague Professor Michelotte, to whom I communicated these results, wished me to produce them at the Cabinet of Philosophy in the University, where the experiment was repeated under his own eyes.

I shall refrain from describing at present other results obtained by attempting the solutions of various metallic salts: in general the analogy between the effects produced and those of the hydro-electric currents appeared perfect; at least when due regard was given to the continuity of these, and to the intermitting and fugacious nature of the magneto-electric currents; - to the constant direction of the former, and the alternate opposition of the latter. At present it is not easy to predict by what the means of exciting and increasing the chemical efficacy of the magneto-electric powers will be limited; but it is certain that such a character, highly interesting as it is in the philosophy of imponderable agents, deserves to fix the attention of men of science.

Turin, Oct, 12, 1832.

LXXX. Notes on the History of English Geology. By William Henry Fitton, M.D. F.R.S. \&c.

[Continued from p. 275.$]$

I $\mathrm{N}$ this enumeration of authors, which we have now brought down to the period when Geology, as a branch of inductive science, may be said to have had its birth in England, we have 